\title{
A LITERATURE REVIEW OF SUPPLY CHAIN RISK MANAGEMENT IN AUTOMOTIVE INDUSTRY
}

\author{
N. Yoga Irsyadillah¹ \& S. Dadang1,* \\ ${ }^{1}$ Faculty of Industrial Technology, Department of Master in Industrial Engineering, Universitas Trisakti, Jakarta, Indonesia.
}

ABSTRACT - Supply chain risk management (SCRM) has a really strong connections with the entire production chain performance across the world and the relationship between stakeholders and partners. It's designed in terms of minimizing risks and enables companies and also organisation to provides long term benefits to all stakeholders and establish a competitive position. Especially, in a complicated and slow-growing industry like Automotive Industry. The automotive industry including passenger vehicles and also commercial vehicles as one of the most important industry segments, were forecasted to fall to 59.5 million units in 2020 , down from a peak of 79.6 in 2017 in their Global sales. In facing this kind of risks and issues we need to analyze deeper about the SCRM implementation in this industry. The implementation of SCRM system in this industry should be structured well to manage both routine and extraordinary risks, such as economical crisis, global pandemic issues, or even other unexpected event. The risks should be managed proactively and reactively, with monitoring customer's needs, changes in the chain, and suppliers also competitors technology enhancement and strategies to enable quick reaction to events and proactively identifying risks and implement actions to prevent or minimize their impacts. The basic SCRM process consists of Defining, Assessing, Mitigating, and Monitoring risks in the supply chain. The objectives of this paper is to analyze how far SCRM has been used to manage the risk factors in Automotive Industry's supply chain in three different segmentation perspective, and the importances of it's implementation in the industry. To achieve this objectives, we performed a qualitative, applied and exploratory field study of the development trend of automotive Industry across the world, Asia, and Indonesia (Global, Continental, and Regional) in terms of gaining more insight about the latest development trend of SCRM implementation in various segmentation. The data were collected by doing literature review from previous published research related to SCRM in Automotive Industry. The results of this research indicated that Competitive orientation no longer relies on products/services, but on the ability to manage supply chain risks. This characteristic places the role of information and communication technology as the very important issues. Thus, system thinking and data management becomes the main choice in implementing and developing SCRM in winning business competition.

\section{ARTICLE HISTORY}

Revised: $14^{\text {th }}$ September 2020

Accepted: $30^{\text {th }}$ September 2020

\section{KEYWORDS}

Supply Chain

Risk management practices

Supply Chain Risk Management Automotive Industry

\section{INTRODUCTION}

After World War II, the automotive industry was seen as a pillar and had a significant effect on economic growth in both developed and developing countries. The automotive companies that dominate around $60 \%$ of the world market are the big Auto company such as Ford, GM, and Toyota. Although the company are the market leader in the company's home country, globally the sales of their products continue to decline in line with breakthroughs made by other automotive companies from Japan and Germany. The car industry also witnessed the loss of mainly smaller US and European producers and a surge in imports, particularly from Asia [1]. Most major car companies now compete globally, through ownership and investment in factories rather than through finished vehicle trade. With so many dynamic challenges and uncertainty events ahead, automotive players should take steps now to improve their business and emerge stronger.

The automotive industry including passenger vehicles and also commercial vehicles as one of the most important industry segments, were forecasted to fall to 59.5 million units in 2020, down from a peak of 79.6 in 2017 in their Global sales [2]. It is impossible to predict precisely the future of trends and development of automotive industry, but no matter how successful the automotive shift to autonomous, electric, or even shared vehicles is, the trends, operational, and composition of automotive factories will change in radical ways. It will be even worst to see the growth of this sector especially when each industry couldn't maintain their Supply Chain Risk Factors. Since, the cooperation and relationship between stakeholders in this industry influenced strongly by Supply chain risk management (SCRM). Where the SCRM itself designed to enables company or even organisation to provides long term beneficials to all stakeholders and to develop and establish competitive position by minimizing possible risks of the entire chain [3]. 
Technological enhancement, improved quality of life together with research and development that drive many changes to the business climate, especially the business with the characteristics of Automotive Industry. Since, today's business challenges are not just the success of selling goods or services to the customers. There is a shift in orientation of this mindset at this time, namely the success of selling goods and services is not due to an effective marketing strategy but the result of risk management's success. Risk management is a process of identifying, assessing, analyzing and acting on various uncertainties that are believed to trigger failure. This definition very clearly emphasizes risk management in every function (procurement, production, quality and engineering) and every line in a company [3]. In its development, business strategy is no longer oriented towards competition between companies but competition between supply chains from one company to another.

In this dynamic era, Supply Chain Management (SCM) is no longer considered a new thing for most of the companies all over the world. Various companies have implemented SCM in their business to improve the efficiency of logistics processes. SCM is a concept that concerns about the relationship between all stakeholders in the chain and product distribution patterns until the end customers that can replace traditional distribution patterns. This new pattern concerns about distribution activities, production schedules, and logistics. Where it involves various members, each of the member playing a significant role and aggregating value to the final result [4]. Moreover, it's very important to understand that supply chain is not only as a relation between a supplier and the customers, but shown as an interconnected network, where the essentials (cost, quality, and risk) of a product offered is a function of the performance from the entire network.

In connection with the risks involved in SCM, risk management plays an important role in keeping the supply chain system from being disrupted. Risk management plays a very important role in the supply chain system, since a company or organisation will hardly predicted precisely what will happen in the future of their chain. These risks, may comes from various events, such as disaster, economic crisis, or even Global Pandemic that can lead to major consequences to the company. To face this kind of issues, there is a key area of interest named as Supply Chain Risk Management (SCRM). SCRM designed to develop various strategies for Defining, Assessing, Mitigating, and Monitoring risks in Supply chain [6]. The cycle that shown on Fig.1 give a brief explanation about the workflow SCRM as an important key in SCM itself.

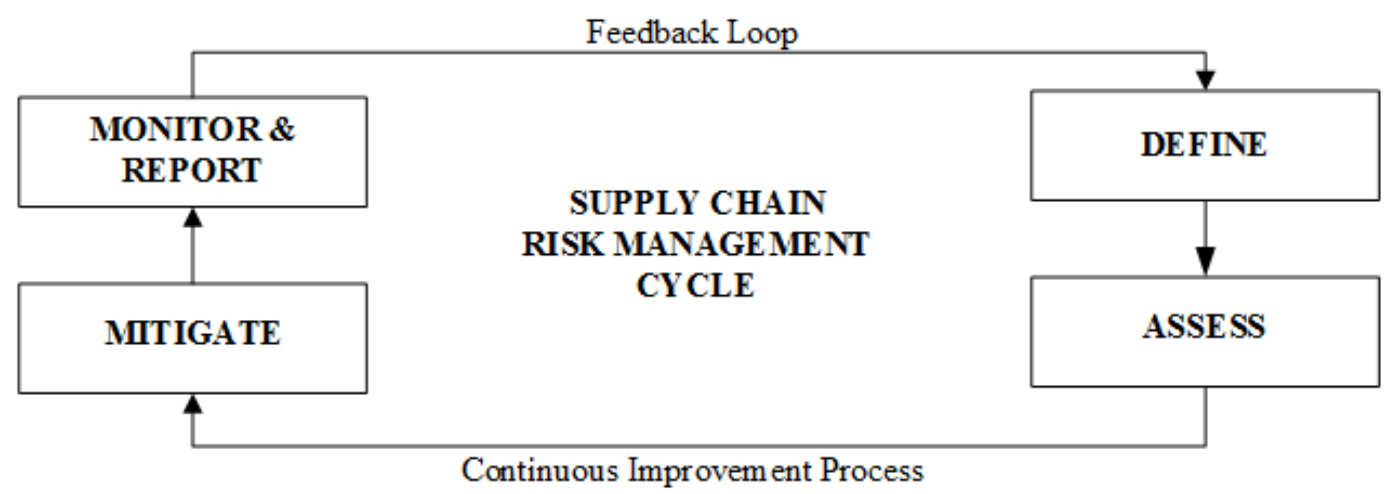

\section{Figure 1. Supply Chain Risk Management Cycle [6]}

The SCRM Stage begin with risk definition, a process of determining the sources of risks along the supply chain. This stage requires decision makers to understand well the series of activities carried out along the supply chain. Every activity needs to be analyzed the potential events or phenomena that might cause uncertainty. Risk assessment is the next stage which aimed to assess the level of risk that will occur based on the impact that may arise from the risks itself. The risk level value is the quantification of the likelihood of an event occurring to a company and its impact. The stage followed by the Mitigation stage, which consist of decision making process of how a company tackle the risks issues in response to the risk assessment results. This stage is a reflection of the company's readiness to face the possible risks. And the last stage is the monitoring stage, where the company execute the implementation of risk management actions whether they go according to the mitigation plans or not [6]. The monitoring process needs to be carried out as a control activity because the business environment is dynamic. This monitoring stage is the process of measuring performance to become input for management. If the implementation of risk management measures is not successful, management can take action to re-assess the risks as soon as possible so that the risk impact will not be too big for the company [7].

We contend that in order to develop a better understanding of the mentioned issues above, a systematic review of current State of the art is needed. Nevertheless, a review of SCRM studies from 1995 until 2009 indicated that the study of SCRM implementation were limited, and these have only partially adressed the implementation of SCRM in automotive industry. In a supply chain context the increased risk is partly the complexity of the network as a result of external sources. A study from Finch (2004) states that networking between organisations can increase a company's risk factors, especially when dealing with small and medium business partners. Meanwhile, according to Tang (2006) supply chain risk is classified into operational risk and disruption risk. The level of dependence and complexity of the current supply chain network makes the supply chain as a whole more vulnerable to disruption. Any disruption that occurs within one of the supply chain players can affect the supply chain network as a whole, such as the cessation of 
the flow of information and resources from upstream to downstream in the supply chain. This can cause an imbalance between supply and demand. Therefore, risk in the supply chain can be defined as disruption of the flow of information and resources in the supply chain network due to discontinuation and uncertain variations (Juttner, 2005). Different than the previous researches, In response to current disruption that feels by most of the industry at the beginning of 2020 , this study aimed to create a literature review to give different insights about the trends and development of this issues specifically in automotive industry across three different segmentation perspective (Global, Continental, and Regional).

From these explanations, we can see how important is the role of SCRM in the industry, especially for the case of Automotive industry. This study conducted, to show the needs of SCRM to be implemented by the Automotive company in preventing future loss caused by undetected risks. Moreover, this study would like to contribute to SCRM Literature with the aim of analyzing how far SCRM has been used to manage the risk factors in Automotive Industry's supply chain in three different segmentation perspective, and the importances of it's implementation in the industry by exploring the SCRM practice of automotive industry. To achieve this objectives, the study performed a qualitative, applied and exploratory field study of the development trend of automotive Industry across the world, Asia, and Indonesia in terms of gaining more insight about the latest development trend of SCRM implementation in various segmentation. The data were collected by doing literature review from previous published research related to SCRM in Automotive Industry. In General, this study begins with the review of past studies of SCRM implementation in automotive industry and a clarification of SCRM construct using the methodology applied follows. Continued by the findings in three different perspectives, result and discussion, and ended with conclusion.

\section{METHODOLOGY}

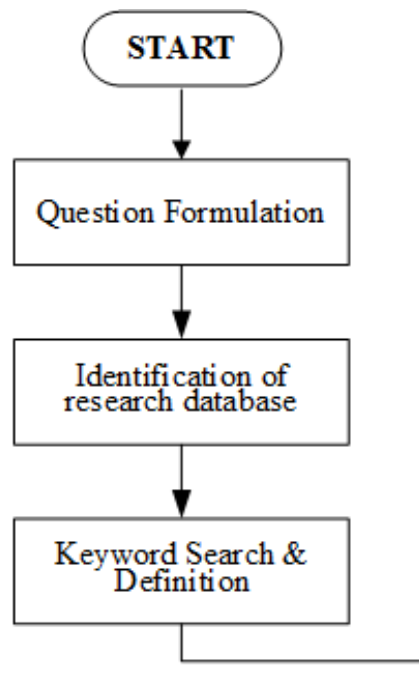

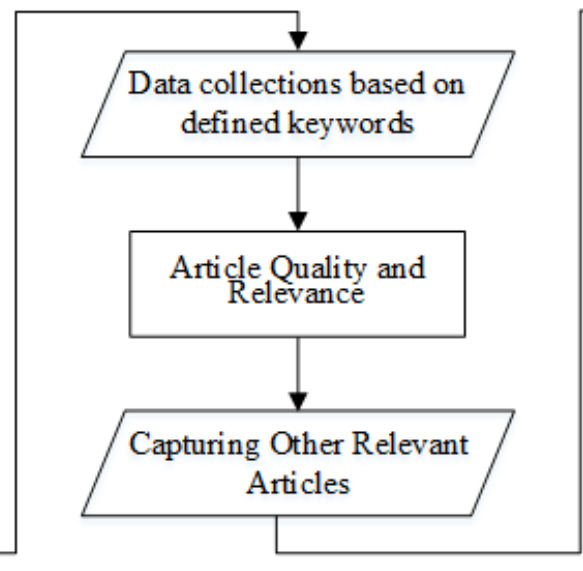

Figure 2. Research Methodology

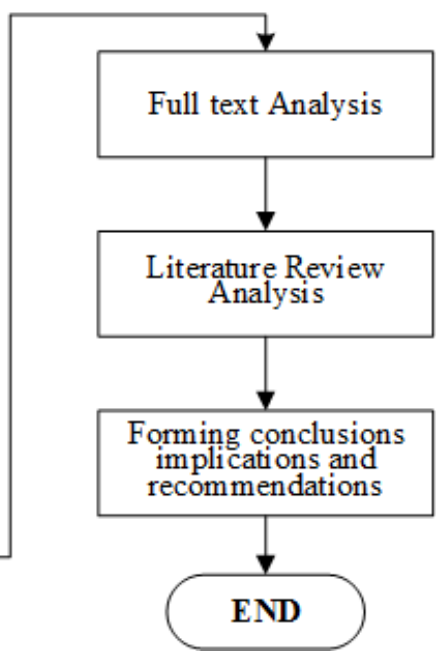

In this research we started with formulating the clear question of this research regarding SCRM in Automotive industry at the first place. Formulating the question about how far SCRM has been used to manage the risk factors in Automotive Industry's supply chain and the results of it's implementation in the industry in three different segmentation perspective, started from World scope, Asia, and Indonesia (Global, Continental, and Regional). This stage continued by research database Identification regarding SCRM in Automotive industry. Followed by defining Keyword and related researches on the relevant topics together with Data collections based on the defined keywords. This study conducted screening to over than 110 papers related to SCRM and automotive industry. The stage continued with checking article Quality and relevancy and Capturing Other Relevant Articles for completing more information needed, that resulted with 85 papers related to SCRM after the screening process conducted. All the information from the collected researches will continued by Full text Analysis and Literature Review Analysis. These will lead to conclusions implications and recommendations formulation.

\section{INFORMATION BACKGROUND}

\section{Supply Chain Risk Management in Automotive Industry}

In the midst of this uncertainty era and dynamics condition of Global market, added by various unxpected events such as trade war, and Global pandemic have created high risks for the automotive industry in general. The supply chain in the automotive industry is becoming more complex than other industries because of its hierarchical structure as well as the conditions of the global sales and supply area that keep declining [8]. The SCM of Automotive industry have been proven to be facing risks obtained from globalisation. Which disrupted the SCM flow from the 
industry or even the continuation of the production. In facing this situation, a lot of the automotive company have increased their SCRM activities to prevent future loss. Most of the companies, increasing their SCRM activities by defining their SCM's weak links of the chain [9]. Although, the review and research that focusing on SCRM implementation in the automotive industry were limited. Even a study on automotive industry in German also found that the SCRM implementation's survey in other parts of the world were lacking [10]. Moreover, a study from one of the automotive company in South America, showed several activities that oftenly associated with SCRM practices. Started from assigning dedicated person as the Chief Risks Officer to control and plan mitigation activities of the company, SCM communication improvement, and several training for the SCRM and business continuity management. In facts, they were also build their factories near to their suppliers to maintain the ongoing supplies rather than doing complex forecast activities [11]. But, although these are some good steps in preparing the SCRM in a company. Surprisingly, they refused to develop contingency plan and risk assessment in terms of developing SCRM in their company, even they were vulnerable to debt and credit and facing bigger risks like union regulation, property damage and theft risks [12].

Like most of the other Industry, Automotive industry also seeing market declines for a variety of related reasons. One of them is unoptimized implementation of SCRM in the industry itself, while risks are the consequences in a business, so it's important for companies to apply the concept of holistic, cybernetic and effective thinking to manage risk that included in SCRM. Yet, this industry has been a challenging field for SCRM research and implementation. In facts, automotive industry still categorized as infancy in SCRM implementation [13]. In terms of increasing the penetration of SCRM in this industry, we need to conduct risk profile development based on this industry characteristic. This will be a guide to start SCRM process penetration in most of the Automotive companies. The facts that SCRM is becoming popular in other industry, should spur Automotive Industry to put deeper concern in SCRM that will increasing the understanding of risks management, prevent even bigger future loss, create solid understanding regarding vulnerability area, and resilience of the SCM improvement [14].

Risks are the unexpected events that resulted in losses for the company. These are the event that will occur in the future that characterized by uncertainty and lack of information. As a result, there are two types of risk, namely predictable and unpredictable. These two types only reflect the involvement of many factors and the level of complexity of the situation the company is facing in the future by implementing SCRM [15]. SCRM strategies are actions taken by company or organisation to move and mitigate the identified uncertainty from various risk sources [16]. The maturity of the SCRM implementation can be seen in the times when a risk strike globally and generally in various industry, like what happened during Trade war and Global Pandemic in 2020. Even the automotive industry was bracing for a brutal year before the COVID-19 Global Pandemic outbreak. While this industry is expected to realign in ways that could have a profound effect on the eight million people worldwide who work for automotive industry. The current condiiton is an incredibly dynamic situation, where these scenarios are designed foremost for robust and thorough contingency planning and not for predictive, and we can see the maturity of SCRM penetration in Automotive Industry by overviewing the condition after these risks striked out. Automotive companies all over the world with tens of thousands of industry employees are temporarily out of work, factories closed, thousands of dealer's traffic has stalled, and distributor are struggling to make sales, and most of the company facing difficulties in payroll [17]. It's shown how important SCRM to be implemented, in preventing worst things to happened in the midst of crisis.

\section{The Current Situation of Automotive Industry}

As it shown on figure 3 , The novel COVID-19, classified as the Global pandemic by WHO, revealed a rapid global spread \& high infection rates with eight millions reported cases happened worldwide [23]. The COVID-19 pandemic has forced automotive manufacturers in various parts of the world close their production facilities. At the same time, demand for automotive industry has dropped sharply in line with significant dropping number of public purchasing worldwide [19]. The COVID-19 outbreak erased around \$ 6 trillion USD in just a single week on February caused by the uncertainty and fear from the community, and public rational assessment about dropping profits from most of the company during this pandemic outbreak [20]. Even the Top 10 largest company of the world striked out by the combined loss over \$ 1.4 trillion USD. In line with the dynamic changes of public perception that this virus will only remain in China, but in facts it's spreading globally and rapidly across the world. The situation even getting worst since the majority of the Government and authority instructed the community to stay at home and implementing Lock down regulation, and travel ban that affecting various companies starting from aviation, manufacturer, automotive, and other industry [21]. The COVID-19 outbreak could prolong the pace of the Global automotive industry. Apart from the influence of global pressure especially China, as one of the main component exporters in the automotive sector, and the facts that they were implementing Social distancing restrictions, Travel ban, and Lock down in a number of parts of their states that are also being extended, and implicate to raw materials and components shortage of the import dependent country [22]. 


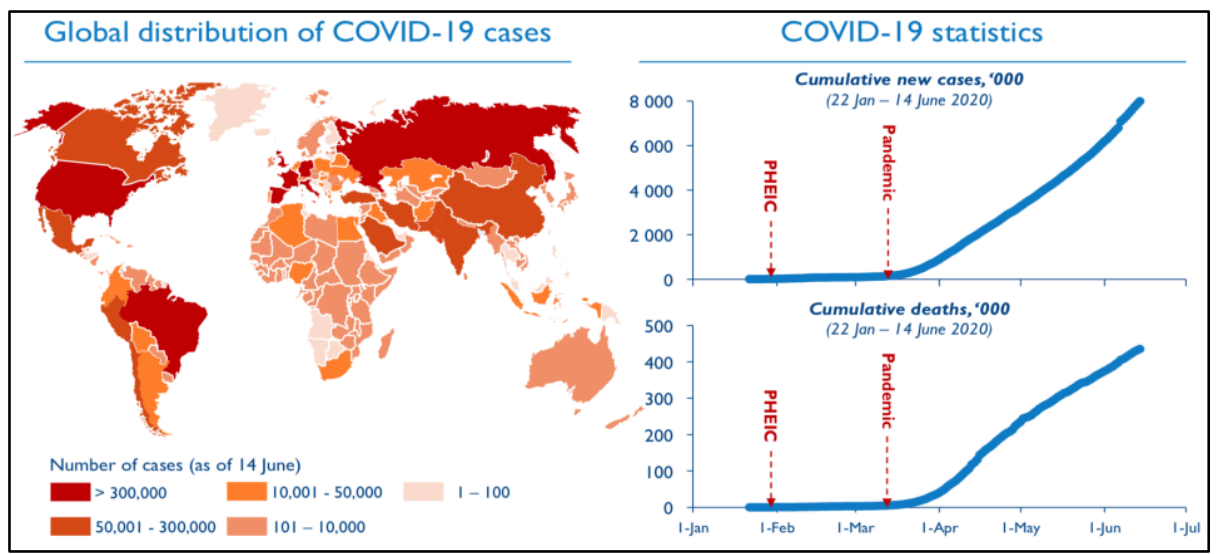

Figure 3. Current Situation due to COVID-19 Pandemic [23]

Meanwhile, business and industrial activities must continue their operations immediately in order to save various fields in the Global automotive sector and the country's economy. In automotive perspective, a lot of import dependent country facing serious difficulties due to import regulations from various country. Most of the major exporting countries like India, China, and Japan also depends on these import dependent country due to their consumption and transaction rate of the automotive commodities [24]. Significant reduction in Global supply chain activities, and dependency of materials and imported goods from country like China, led the industry to difficulties in continuing their production and sales activities caused by supplies shortage. Aside from supplies shortage, this condition also led to the increases in price of the remaining improted supllies stocks, that also triggered inflationary pressures on the price [25]. One of the worst thing is that the automotive industry is a system that we cannot see it only from the manufacturing side. It wil also connected with other industry like financing and insurance companies, so the disruption on this industry will also become the additional factors of economic recession. If we would like to see deeper from the manufacturer side, it's not just talking about the car manufacturing plant but on the other hand there are thousands of suppliers and distributors involved. So, the impact of this condition will be broad and significant to many sectors.

However, for the import dependent country to find the replacement other than China will be so difficult, since many countries closed their border and shipping point to prevent more impacts from the pandemic, and for sure caused stifled in international trade at this time. Added by the previous events like trade war, Post world war II, and economic disruption that already increase the unemployment by $2 \%$ [27]. That makes, this period totally different and even more complex compare to the old crisis that this world faced. It's the double combination of supplies disruption, demand declines, and economic tools limitations. Monetary stimulus almost have no chances to help sustain the incoming risks. Overall, the world can conclude that the potential impacts of this crisis are larger than any previously seen in history [28]. Most of the country, exporters or even importers will most likely feel the impact of this big disruption. Even the data from World Trade Organization (WTO) stated that the global trade will fall up to $32 \%$ this year due to the global pandemic [29]. And moreover, the Supply chain networks is another channel that will received the negative impacts of the global economy condition. Especially for the companis that haven't prepared mature SCRM system in their organisation. Since the functioning of Global supply chains has been disrupted and generating negative impacts through different levels of supplier networks. It will also impacted on the increment of cost of business for Automotive Industry. As the business process disrupted the world has been hammered by one of the biggest risk to happened in the modern era, shortage of supplies, factories closed, transportation route collapsed, Government regulations, and various constrains that make it even worse. In facts, $75 \%$ of companies all over the world are facing disruption on their SCM system. Lead times and Delivery times of the system have also increased significantly due to the supplies shortage [30]. With all of the impacts that just happened in various industry, it's questioning the SCRM system of many companies.

Grlobal Forecast of Automotive Production

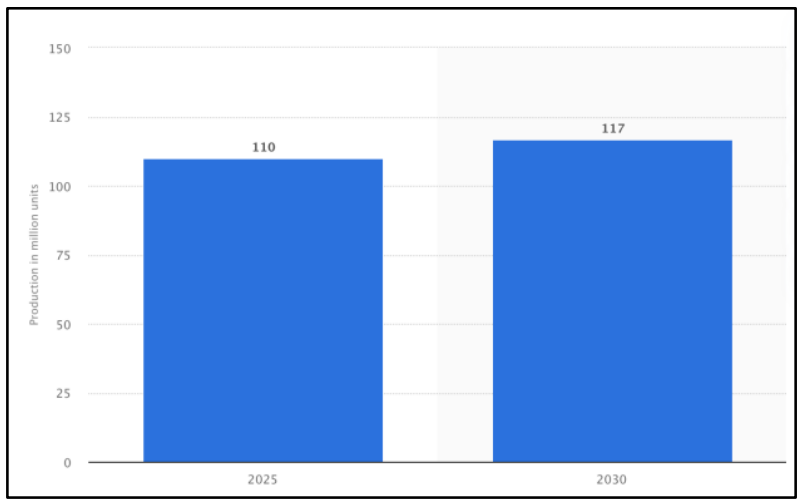

Figure 4. Forecast of Global production forecast of vehicles (2025-2030) [6] 
In three consecutive years, global automotive production decreased by 2.6 percent, to 89 million vehicles in 2020. This condition occurred in line with the decline in demand from the automotive market in China, the United States and Europe. Added by the facts that The coronavirus outbreak has heavily impacted the manufacturing industry especially automotive sector [31]. Even the chart on figure 4 shown that there will be increment of Global production of vehicles in the next 5 years (110 millions to 117 million unit/year), but it will be dominated by shared mobility, electric vehicles, autonomous, and connectivity solutions. If the automotive companies couldn't analyze the risks behind this trend. It will give such a big disruption for the company at the future [32]. It means, that if the shared mobility, electric and autonomous vehicles striked out it will be potential risks for the company. It could means factories closure, significant cut on resources, and market loss potential. As the company need to make a big decision on whether and how all of this futuristic production makes economic sense. It can be really put the company profits at risk, as the business complexity transferred to the supply chain and the value at the same time [33]. The needs and urges of creating a big changes, by changing the primary product of the company to the futuristic style vehicles, and evolving the factories at the same time for being capable in managing efficient operating cost during the period of critical change. It shown us that SCRM is really importan to be prepared in a long time before possibles risks could happened. Most likely, electric and autonomous vehicles will become the majority on the road by the year of 2030. Even stated in the global survey, that $60 \%$ of respondent from customers experienced the feeling of fully changing to electric and autonomous vehicles [34].

\section{Automotive Industry Development Trend Across The World (Global Perspective)}

\begin{tabular}{|c|c|c|c|c|}
\hline \multirow{2}{*}{$\begin{array}{l}\text { Countryl } \\
\text { Region }\end{array}$} & \multicolumn{2}{|c|}{ Vehicle Sales } & \multirow{2}{*}{$\%$ Change(E) } & \multirow{2}{*}{ Comments } \\
\hline & 2019 (M Units) & 2020E (M Units) & & \\
\hline China & 25.7 & 21.9 & $-14.8 \%$ & Continues to make a V-shaped recovery \\
\hline us & 17.6 & 13.4 & $-23.9 \%$ & $\begin{array}{l}\text { Sales continue to decline with the pandemic having a } \\
\text { prolonged economic impact }\end{array}$ \\
\hline Europe & 18.3 & 13.6 & $-25.7 \%$ & Bounce back \\
\hline $\begin{array}{l}\text { Rest of } \\
\text { World }\end{array}$ & 28.4 & $\begin{array}{c}\text { O Counterpoint } \\
23.0\end{array}$ & $-19.0 \%$ & Automakers resuming partial operations. \\
\hline Total & 90.0 & 71.9 & $-20.1 \%$ & $\begin{array}{l}\text { Extended lockdowns and pressure on consumer } \\
\text { confidence impacting sales. }\end{array}$ \\
\hline
\end{tabular}

Figure 5. Impact of COVID-19 To Global Automotive Sales [23]

From the table that shown on Fig.5 related to impact of COVID-19 Global pandemic to the global automotive sales. We can see that the decline in sales is happening in every part of the world without exception. All of the sales decline are more than $10 \%$. We can see also that extended lockdowns and pressure on consumer regarding living in the middle of the uncertainty condition impacting global sales. Significant reduction in Global supply chain activities, and dependency of materials and imported goods from country like China, led the industry to difficulties in continuing their production and sales activities caused by supplies shortage [35]. Entering the year of 2020, the automotive industry is starting to face critical times, even many experts said that this industry is likely to be sluggish until the year of 2025 . This condition forces many automotive companies to find it difficult to find large profits. At the end, many employees were cut by most of the companies to save the company's financial health and cashflow. Not to mention the facts that in three consecutive years (2018-2020), global automotive production decreased by 2.6 percent, to 89 million vehicles in 2020. Even it forcasted that the automotive market would sink by 10 million units in 2020 compared to the time when this industry had reached its peak on 2017 [36].

Most of the company that successfully bounce back or continuosly make a V-shaped recovery step by a step, already having a mature SCRM system. Well the rest of the companies in this industry, have not prepared their SCRM plan for this kind of risk [37]. Even this kind of Global pandemic is the worst one during this modern era, but SCRM will also count on this kind of risks. Although it does not rule out that company's loss would still happened, but the mitigation plan will prevent the company's loss to get any bigger. It's perfectly shown how important SCRM to be implemented, in preventing worst things to happened in the midst of global crisis. Most of the company are now started to put more concern on risk management, caused by hammered with this big risk that already happened. But, most importantly what we need to do are planning the SCRM not just for a short term period, but for a long term period with a solid commitment within all stakeholders in the chain. In a situation like this, for sure many automotive companies that have not created SCRM system must be prepared to offer severance pay, cut working hours, and seek volunteer or part time workers. Even so, it is not clear how many types of work are no longer needed in this kind of crisis. But it could be an invaluable lesson to formulate the SCRM for the long term [38]. What shouldn't be missed by these 
companies are the opportunity to bounce back from the failures, build a solid SCRM foundation, and prevent to repeated the same failures over and over again by doing comprehensive planning.

Automotive Industry Development Trend Across Asia (Continental Perspective)

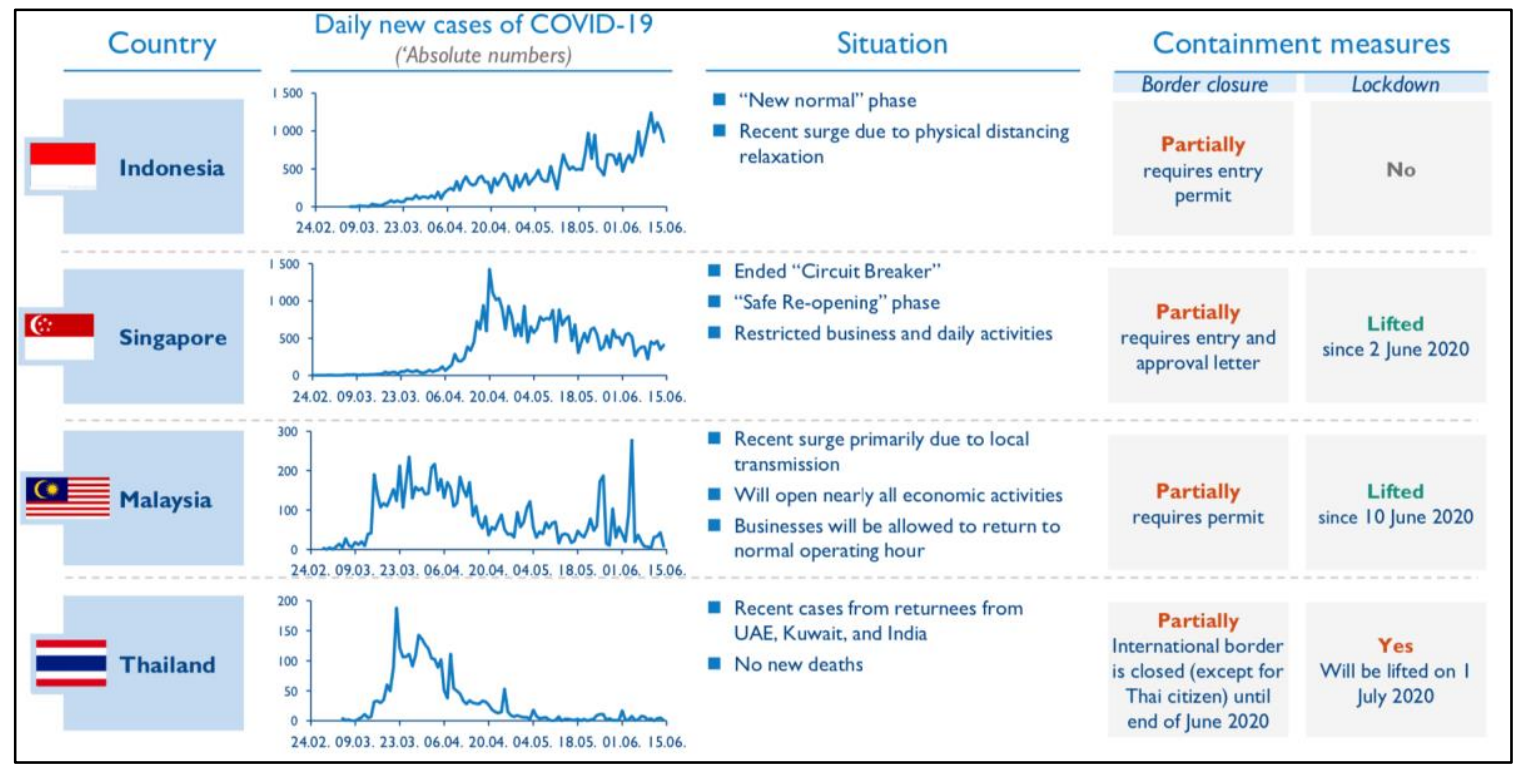

Figure 6. Industry Condition Across Asia [23]

Several countries in Asia have lifted and are going to lift the lockdown measures, however, travel restriction is still in place caused by the Global Pandemic. But most of the country who lifted the lockdown regulation up, was facing the second waves and need to do the same thing over again [23]. Moreover, there are also several country that sucessfully pressing the incline rate of COVID-19 patients by the right regulations from the Government (Such as : Thailand \& Vietnam). From the automotive perspective, we should highlighted that Asia economic integration on automotive divided into two different category. The first one is the automotive production that supported by high percentage of local contents and integrated manufacturing process (above 60\%) that mostly conducted by Mitsubishi, Honda, and Toyota in all over asia continent. This type of category have a relatively well developed supplier and supported by local Research and Development team. On the other hand, the second category is the automotive production that supported by low percentage of local contents (below 40\%), and most often done in a country with a weaker supplier quality. And most of this category, does not supported by local Research and Development team with smaller market share than the first category [39]. In this kind of times when the economy become unstable, both of the category will received a significant impacts. Even though the consequences for the $1^{\text {st }}$ category seems limited than if we compared the possible influence on the $2^{\text {nd }}$ category that much clearer. If we analyze the problems from this perspective we can see that the automotive company with the first category will be most likely faster to bounce back after the condition become more stable. Since we can see that localized resources of their plant is above $60 \%$. It will make the managerials could plan the $\mathrm{V}$-shaped recovery plan more easily than the $2^{\text {nd }}$ category. But, it will also depends on the rest of the materials needs that supplied to that country.

Because as we know from the chart on Fig.6 most of the country still implemented some delivery restrictions caused by the condition of the pandemic. So, it will give a significant disruption to the continuation of the production in each category. From this segmentation perspective of Asia continent, we can also see the same things happened to their automotive industry. And most of the manufacturer from the $2^{\text {nd }}$ category will be even harder to bounce back due to their maturity level of SCRM in their own company [41]. It's also helping to show the importances of SCRM to be implemented in a company, to prevent worst things to be happened in the midst of crisis. Most of the big companies that included in first category already started SCRM in their company, even it's not significantly avoid them from this big crisis. But, they still shown positive developments in sales at the beginning of the second semester of this year. Companies are stepping up to the challenge created by the global pandemic coronavirus outbreak. They are supporting governments and the community in developing and supplying various products that align with the needs in the new normal era of this pandemic. The common homework for various party nowadays are pushing back consumer's confidence and creating the economy that are inextricably linked. To avoid the decline in sales and strengtening the preparation of automotive industry to face these hard times beyond until a vaccine is developed and made widely available. 
Automotive Industry Development Trend Across Indonesia (Regional Perspective)

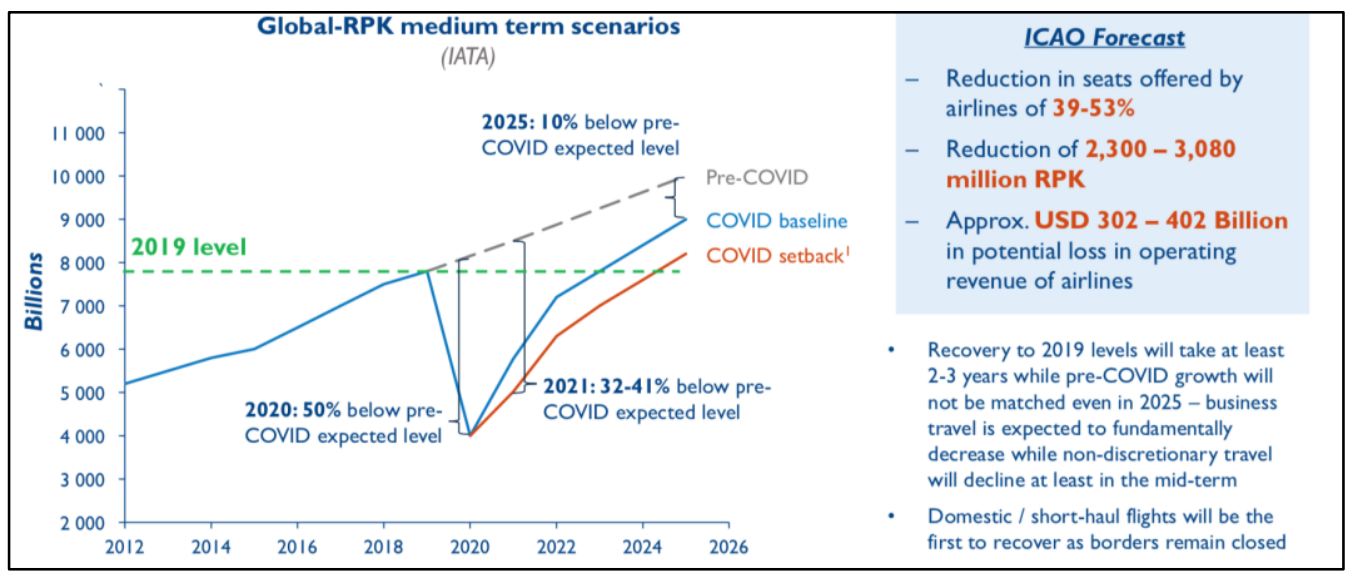

Figure 7. Forecast of COVID-19 Impact to Passenger Transportation [23]

Continuing the study to narrower segmentation, which conducted regionally for Indonesia. The situation of Global Pandemic that striked out in 2020 give a significant impact to the automotive industry as well. The impacts to this industry can easily be seen from the significant decline in demand for cars in Indonesia at the beginning of the year. The regulations created by the Indonesian Government known as Indonesia Large Scale Social Restrictions (LSSR), forced the automotive industry to stop their production for two to three months. This regulation not just exist for the automotive industry, but to the other industry as well except the industry that related to pharmacy and health care [42]. On the sales side this industry was hit hard with significant decline in sales, moreover it was also lead the automotive companies in Indonesia on layoffs of millions of workers has also contributed to reducing car sales. Without help from various party, this industry could collapse. While In facts, this industry absorbs millions of workers in Indonesia and give quite significant contribution to the Indonesia's GDP (Gross Domestic Product), around 3.98 percent in 2019. The National automotive industry also facing difficulties in the supplies shortage of components and raw materials. The supply has stalled due the regulations from exporting country like China that have been implementing lockdown policies in tackling this Global pandemic. These issues implicates in motor vehicle manufacturing industry as well that forced to look for alternative supplies to maintain stable production. [43].

As we can see also from the Fig.7 about the forecast of COVID-19 Impact to Passenger Transportation, Passenger transportation also significantly affected by this situation due to travel restrictions and Indonesia Large Scale Social Restrictions (LSSR). We can see from the graph, that it's forecasted V-shape recovery will take at least 2-3 years causing by this pandemic. In facts, if this pandemic continuosly caused panic and customer's confidence and trust, It could lead to global economy and trade significant decline. However, the consequences of this pandemic will not be equally distributed throughout the economy [44]. Although we don't have historical benchmark that we can use directly, we can push the company and the regulator which is the Government to work together on focusing bringing back cutomer's confidence and policies that will make the situation become more stable [45]. As of today, Indonesian people and most of people from the other country entering new normal regulations. The community should hand in hand in bringing back the economy with putting serious concern to the health protocol and pandemic latest trend as well. Moreover, for the automotive industry perspective just like the study on the other 2 different segmentation, the company need to take this opportunity as the baseline for start to implement SCRM system in their organisation. In this uncertain environment, it is difficult to forecast the economic impact day by day. But with the right mitigation planning using a solid SCRM system, they can manage to survive and passed on the other risks in the future.

\section{RESULT AND DISCUSSION}

From this study we can see that in the future the Automotive industry will be so much more dynamic and challenging. If the automotive companies couldn't analyze the risks behind this trend. It will give such a big disruption for the company at the future. We can see from the study of automotive industry across three different segmentation perspective in this paper, that these risks exist for every level of segmentation, from global, continental, to regional. We can see also that immature SCRM planning, preparation, and implementation could lead the company to a bigger loss in the future. As the company need to make a big decision on day by day in the midst of the uncertainty, SCRM system will be the key to tackle several issues caused by the risks and uncertainty. The automotive industry has experienced a transformational evolution in the past two decades. Historically, the industry operates according to a 'push' system. In this kind of system, Sales and marketing take significant part in forecasting the market demand and provide and completed this forecast with other related teams (Manufacturing, design, financial, and engineering) to determine production volumes or even models [46]. With the development of the internet, data has become far more accessible to car manufacturers and all stakeholders of this Industry. The automotive industry focuses primarily on the usage of Big data analytics, lean JIT manufacturing process, and its supporting technologies enhancement. In the midst of this 
dynamic market and the era of uncertainty, Automotive industry who know how to leverage their data and make informed could led them to have a helpful guide in their decision making process.

The development of SCRM in the context of increasing the competitiveness of a company or an organisation, especially in a complicated and slow-growing industry like Automotive Industry are the effective use of information and communication technology enhancement. The automotive supply chain is very complex and consists of many processes, when connected together forming a supply chain from customers back to various levels of suppliers. The risks of this industry itself arises because of uncertainty, like Global pandemic, trade war, an various unexpected events. On the other hand, uncertainty arises because lack of information and analysis, together with inaccurate forecast or prediction. Lack of information itself arises because of lack of data availability or even data limitations. That is the actual key to success in risk management, the data availability itself. On the supply chain side, the interactions between all stakeholders in the chain are always related to information. This characteristic places the role of information and communication technology as the very important issues. This reveals that the automotive industry operates in a very competitive environment characterized by increasingly dynamic demanding customers all over the world.

\section{CONCLUSION}

Competitive orientation no longer relies on products or services, but on the ability to manage supply chain risks. This proposition is formulated with the idea that an item can compete in terms of price or quality or the delivery if and only the supply of materials and goods is guaranteed. Supply will run smoothly according to plan if there is certainty, however the facts show certainty in the business is uncertainty itself. SCRM is an effective tool in managing uncertainty. Uncertainty arises because lack of information and analysis, together with inaccurate forecast or prediction. Lack of information itself arises because of lack of data availability or even data limitations. That is the actual key to success in risk management, the data availability itself. On the supply chain side, the interactions between all stakeholders in the chain are always related to information. This characteristic places the role of information and communication technology as the very important issues. From these results, we concluded that the Automotive companies should place the importances of SCRM as their top list priority in the midst of this era of uncertainty. This industry should think how to leverage their data and make informed effectively in minimizing the risks of this dynamic era to their industry that could led them to have a helpful guide in their decision making process. Thus, system thinking and data management together with the usage of technology enhancement like Big data analytics and ERP becomes the main choices in implementing and developing SCRM in winning business competition in this era. Then, the development of the SCRM itself becomes an efficient supply chain model that will meet the challenges of customers and producers in the automotive industry.

\section{REFERENCES}

[1] Alvarenga, C. (2012). Why quants should manage your supply chain risk. Harvard Business School Publishing. Accessed July 23, 2015, from http://blogs.hbr.org/2012/11/why-quants-should-manage-your/

[2] Becks, R. (2010). The next big thing: Multi-tier supply chain management. Accessed July 23, 2015, from http://www.scdigest.com/experts/E2Open_11-08-11.php?cid=4840\&ctype=content

[3] Care Fan, Y and Stevenson, M (2018). A review of supply chain risk management: definition, theory, and research agenda. International Journal of Physical Distribution and Logistics Management, 48 (3). pp. 205-230. ISSN 0960- 0035

[4] Choi, T. Y., Dooley, K., \& Rungtusanatham, M. (2001). Supply networks and complex adaptive systems in Automotive Sectors: Control versus emergence. Journal of Operations Management, 19(3), 351-366.

[5] Christopher, M., \& Lee, H. (2004). Mitigating supply chain risk in Automotive Industry through improved confidence. International Journal of Physical Distribution and Logistics Management, 34(5), 388-396.

[6] Ozgur, Ceyhun, \& B. David. (2020). The Effect of Supply Chain Disruptions on Business. College of Business, Valparaiso University \& Kent State University, USA.

[7] Hendricks, K. B., \& Singhal, V. R. (2008). The effect of SCRM glitches on shareholder. Journal of Operations Management, 21(5), 501-522.

[8] Kajüter, P. (2003). Instrumente zum Risikomanagement in der Otomotif Supply Chain. In W. Stölzle \& A. Otto (Eds.). Supply Chain Controlling in Theorie und Praxis: Aktuelle Konzepte und Unternehmensbeispiele (pp. 107-135). Wiesbaden.

[9] Kern, D., Moser, R., Hartmann, E., \& Moder, M. (2012). Supply risk management: Model development and empirical analysis in AutoMobile Sector. International Journal of Physical Distribution and Logistics Management, 42(1), 60-82.

[10] Sustainable supply chain management. J. Clean. Prod. 52, 329e341. Brandenburg, M., Govindan, K., Sarkis, J., Seuring, S., 2014. Quantitative models for sustainable supply chain management: developments and directions. Eur. J. Operat. Res. 233 (2), $299 \mathrm{e} 312$.

[11] Kern Govindan, K., Soleimani, H., Kannan, D., 2015. Reverse logistics and closed loop supply chain: a comprehensive review to explore the future. Eur. J. Operat. Res. 240 (3), 603e626. http://dx.doi.org/10.1016/j.ejor.2014.07.012.

[12] H.Kobayashi, Y.Jin, \& M. Schroeder. ASEAN economic community and the regional automotive industry: impact of ASEAN economic integration on two types of automotive production in Southeast Asia, Int. J. Automotive Technology and Management, Vol. 15, No. 3, 2015.

[13] Nikkei Keizai Shimbun (September 20, 2013) 'Nissan to produce passenger cars in Myanmar from 2015; 10,000 units per year', Nissan, 15 nen kara myanmaa de jōyōsha seisan toshi ichiman dai. 
[14] Agustin, T. and Schroeder, M. (2014) 'The Indian automotive industry and the ASEAN supply chain relations', pp.50-113, in Research Institute Auto Parts Industries, Waseda University (Eds.): Automobile and Auto Components Industries in ASEAN: Current State and Issues, ERIA Research Project Report 2013-7, ERIA, Jakarta [online] http://www.eria.org/RPR_FY2013_No.7_Chapter_5.pdf.

[15] Lecler, Y. (2002) 'The cluster role in the development of the Thai Car industry', in International Journal of Urban and Regional Research, Vol. 26, No. 4, pp.799-814.

[16] Sinha, A., Bernardes, E., Calderon, R., \& Wuest, T. (2020). Digital Supply Networks: Transform Your Supply Chain and Gain Competitive Advantage with Disruptive Technology and Reimagined Processes. McGraw-Hill. ISBN-13: 9781260458190

[17] C. Brian. "Auto Companies Will Outlast COVID-19 and Come Out Stronger". Boston Consulting Group (BCG) Global Management Consulting, $21^{\text {st }}$ April 2020.

[18] Swasey, C., Winter, E., \& Sheyman, I. (2020). The staggering economic impact of the coronavirus pandemic. Data for Progress. Retrieved from: http://filesforprogress.org/memos/the-staggering- economic-impact-coronavirus.pdf

[19] Dressler, N. (2020). HOW AUTOMOTIVE COMPANIES CAN SECURE SHORT-TERM SURVIVAL AND PREPARE FOR A POST-CORONAVIRUS FUTURE. Retrieved April 8th, 2020, from https://www.rolandberger.com/en/Point-ofView/How-automotive-companies-can- secure-short-term-survival-and-prepare-for-a.html

[20] Kusiak, A. (2019), Fundamentals of smart manufacturing: A multi-thread perspective, IFAC Annual Reviews in Control, 47, 214-220.

[21] Reichhart, A. and Holweg, M. (2008) 'Co-located supplier clusters: forms, functions, and theoretical perspectives', International Journal of Operations \& Production Management Vol. 28, No. 1, pp.53-78.

[22] Manuj, I., and F. Sahin. 2011. "A Model of Supply Chain and Supply Chain Decision-making Complexity.” International Journal of Physical Distribution and Logistics Management 41 (5): 511-549.

[23] F. Akita. "The New Normal : Logistic \& Transport Industry under COVID-19 pandemic, challenges, outlook, and strategy to recover". Arthur D little Global Management Consulting, $16^{\text {th }}$ June 2020.

[24] Miller, K. 1992. "A Framework for Integrated Risk Management in International Business.” Journal of International Business Studies 23 (2): 311-332.

[25] Xanthopoulos, A., D. Vlachos, and E. Lakovou. 2012. "Optimal Newsvendor Policies for Dual-sourcing Supply Chains: A Disruption Risk Management Framework.” Computers and Operations Research 39: 350-357.

[26] Verbano, K, and C. Venturini. 2011. "Development Paths of Risk Management: Approaches, Methods and Fields of Application." Journal of Risk Research 14 (5): 519-550.

[27] Thun, J., and D. Hoenig. 2011. "An Empirical Analysis of Supply Chain Risk Management in the German Automotive Industry." International Journal of Production Economics 13 (1): 242-249.

[28] Thun, J., M. Drüke, and D. Hoenig. 2011. "Managing Uncertainty - An Empirical Analysis of Supply Chain Risk Management in Small and Medium-sized Enterprises.” International Journal of Production Research 49: 5511-5525.

[29] Lavastre, A. Gunasekaran, A. Spalanzani, Supply chain risk management in French companies, Decision Support Systems. 52 (2012) 828-838.

[30] R. M. Choudry, K. Iqbal, Identification of risk management system in construction industry in Pakistan, Journal of Management in Engineering. 29 (2013) 42-49

[31] H. Thun, M. Druke, D. Hoenig, Managing uncertainty - An empirical analysis of supply chain risk management in small and medium-sized enterprises. International Journal of Production Research. 49, 18 (2011) 5511-5525.

[32] Choi, T. Y., Dooley, K., \& Rungtusanatham, M. (2001). Supply networks and complex adaptive systems in Automotive Sectors: Control versus emergence. Journal of Operations Management, 19(3), 351-366.

[33] Christopher, M., \& Lee, H. (2004). Mitigating supply chain risk in Automotive Industry through improved confidence. International Journal of Physical Distribution and Logistics Management, 34(5), 388-396.

[34] Kern, D., Moser, R., Hartmann, E., \& Moder, M. (2012). Supply risk management: Model development and empirical analysis in AutoMobile Sector. International Journal of Physical Distribution and Logistics Management, 42(1), 60-82.

[35] H.Kobayashi, Y.Jin, \& M. Schroeder. ASEAN economic community and the regional automotive industry: impact of ASEAN economic integration on two types of automotive production in Southeast Asia, Int. J. Automotive Technology and Management, Vol. 15, No. 3, 2015.

[36] Agustin, T. and Schroeder, M. (2014) 'The Indian automotive industry and the ASEAN supply chain relations', pp.50-113, in Research Institute Auto Parts Industries, Waseda University (Eds.): Automobile and Auto Components Industries in ASEAN: Current State and Issues, ERIA Research Project 20137, ERIA, Jakarta.

[37] Sinha, A., Bernardes, E., Calderon, R., \& Wuest, T. (2020). Digital Supply Networks: Transform Your Supply Chain and Gain Competitive Advantage with Disruptive Technology and Reimagined Processes. McGraw-Hill. ISBN-13: 978-1260458190

[38] Manuj, I., and F. Sahin. 2011. "A Model of Supply Chain and Supply Chain Decision-making Complexity." International Journal of Physical Distribution and Logistics Management 41 (5): 511-549.

[39] Miller, K. 1992. "A Framework for Integrated Risk Management in International Business." Journal of International Business Studies 23 (2): 311-332.

[40] Nieger, D., K. Rotaru, and L. Churilov. 2009. "Supply Chain Risk Identification with Value- Focused Process Engineering.” Journal of Operations Management 27 (2): 154-168.

[41] Thun, J., and D. Hoenig. 2011. "An Empirical Analysis of Supply Chain Risk Management in the German Automotive Industry." International Journal of Production Economics 13 (1): 242-249.

[42] Thun, J., M. Drüke, and D. Hoenig. 2011. "Managing Uncertainty - An Empirical Analysis of Supply Chain Risk Management in Small and Medium-sized Enterprises." International Journal of Production Research 49: 55115525 .

[43] y, W. P. (2005). Deep supplier relationships drive automakers' success. Accessed July 23, 2015, from http://knowwpcarey.com/article.cfm?aid=940 
[44] Waters, D. (2007), Supply Chain Risk Management: Vulnerability and Resilience in Logistics, Kogan Page, London and Philadeplhia.

[45] Zsidisin, G.A., Ritchie, B. (2009), Supply chain risk management - developments, issues and challenges, International Series in Operations Research \& Management Science, Vol. 124, pp. 1-12.

[46] Sturgeon, T., Biesebroeck J.V. and Gereffi, G. (2007) Prospects for Canada in the NAFTA Automotive Industry: A Global Value Chain Analysis, Industry Canada, Research Report. 